\title{
Bituminous Pavement Reinforcement with Fiber: A Review
}

\author{
Nuha Mashaan ${ }^{1, * \mathbb{D}}$, Mohamed Karim ${ }^{2}$, Farag Khodary ${ }^{3}$, Nikhil Saboo ${ }^{4}$ and Abdalrhman Milad 5 \\ 1 Faculty of Science and Engineering, School of Civil and Mechanical Engineering, Curtin University, \\ Bentley, WA 6102, Australia \\ 2 Center Transportation Research, Faculty of Engineering, University Malaya, Kuala Lumpur 50603, Malaysia; \\ rehan@um.edu.my \\ 3 Civil Engineering Department, South Valley University, Qena 83523, Egypt; khodary@svu.edu.eg \\ 4 Department of Civil Engineering, Indian Institute of Technology, Roorkee 247667, India; \\ nikhil.saboo@ce.iitr.ac.in \\ 5 Department of Civil Engineering, Universiti Kebangsaan Malaysia, Bangi 43600, Malaysia; \\ miladabdalrhman@siswa.ukm.edu.my \\ * Correspondence: nuhas.mashaan1@curtin.edu.au
}

Citation: Mashaan, N.; Karim, M.; Khodary, F.; Saboo, N.; Milad, A.

Bituminous Pavement Reinforcement with Fiber: A Review. CivilEng 2021,

2, 599-611. https://doi.org/

$10.3390 /$ civileng2030033

Academic Editors:

João Castro-Gomes, Cristina Fael and Miguel Nepomuceno

Received: 9 July 2021

Accepted: 20 July 2021

Published: 23 July 2021

Publisher's Note: MDPI stays neutral with regard to jurisdictional claims in published maps and institutional affiliations.

Copyright: (c) 2021 by the authors. Licensee MDPI, Basel, Switzerland. This article is an open access article distributed under the terms and conditions of the Creative Commons Attribution (CC BY) license (https:// creativecommons.org/licenses/by/ $4.0 /)$.

\begin{abstract}
This paper attempts to display, analyze and discuss the literature affiliated to the previous research data on road surfacing in pavement engineering reinforcement. In this paper, a review of the background and present status of road surfacing is also provided for supportive explanation of the significance of fiber-reinforced asphalt pavement HMA and its role in providing effective and durable surfacing for heavy-trafficked roads. The paper attempts to clarify some of the terms and notions related to the discussions to give the readers the needed background, to be able to actively understand the experiments and discussions. Results from many studies confirm that fiber specifically enhances the optimum bitumen content in the design of the mixture and halts the bitumen leakage due to its asphalt absorbing susceptibility. Fiber modifies the visco-elastic response, susceptibility against moisture, increase resistance to rutting, as well as lowers the pavement fatigue cracking.
\end{abstract}

Keywords: bitumen; pavement; fiber; rutting; fatigue; fiber-asphalt

\section{Introduction}

Bituminous pavement surface usually consisting of a surface layer of mineral aggregate, which is covered with bitumen binder and one or more supporting courses. The ingredients forming this layer can be mainly; (i) bitumen-aggregate mix forming the bituminous base (ii) selected stone, gravel or slag, (iii) cement. The structure of bituminous pavement normally consists of unbound (gravel or stone) layers and bitumen-bound layers above the prepared sub-grade. The top or upper layers of the pavement consists of a bituminous surface, which can be formed of a chip seal (applicable to low volume roads) or on HMA of high quality (applicable to high-volume roads and parking lots). In order to have a bituminous pavement surface that can resist distortion while providing a smooth but skid resistant surface, it needs to be tough. It also needs to be waterproof and strongly bonded to the course or layer beneath to maintain the stability and strength of the whole structure [1,2].

The pavement surface structure as shown in Figure 1 is supposed to tolerate heavy traffic loads as well as provide resistance to water infiltration during wet periods, which can result in deterioration of the pavement surface and lower layers. Therefore, keeping water away from the pavement surface is vitally important and can lengthen the pavement service, as the tire pressure exerted by heavy vehicles or frequent passage of vehicles on the road forces the liquid into the pavement and its lower layers, which, in the long run, can result in the pavement failure and deterioration [3]. The choice of the materials to be used in the bituminous mixture to obtain the coveted properties for the optimal surfacing plays an vital role in design procedure. The primary objective of the design is achieving a durable 
and economical mixture with the following features: (a) adequate bitumen to provide a durable pavement; (b)optimum mixture durability to secure the pavement resistance against heavy traffic loads without deterioration or deformation; (c) sufficient air voids in the compacted mixture to avoid bleeding, flushing and loss of stability brought by extreme moisture and air circulation; and optimal workability to ensure mixture placement without undesirable segregation Ignoring the design steps, such as executing (transport of mix, temperature and dynamic load) and construction might lead to destruction an deformation of the road structure [2].

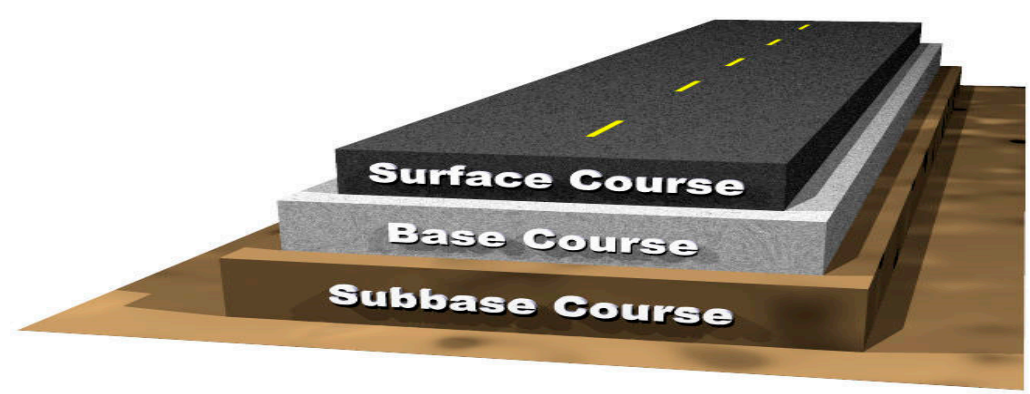

Figure 1. Pavement surface structure [4].

Today, the increase in the volume of traffic on the road and, among other factor, such as axel pressure, loads, insufficiency of high-quality aggregates and high temperature fluctuation in some area, virgin bitumen pavement have suffered various distress and structural failure, which, in the long-term, results in serious problems such as moisture damage, rutting and fatigue cracking [5-7]. The performance of asphalt pavement can be improved through the addition of additives, such as polymers and fibers into the mixture which usually enhances the bitumen stiffness and engineering properties. In this review paper, using different types of fiber in bituminous mixtures reinforcement will be illustrated. Furthermore, discussion of impact of fiber-reinforced-asphalt on enhancing the pavement resistance to deformation.

\section{Bituminous Pavement Reinforcement}

\subsection{Pavement Distress, Surface Deterioration and Deformation}

Damage to bituminous mixtures is caused by heavy traffic loads, especially under extreme environmental and climate conditions. HMA failure is a common problem occurring mostly in both hot and cold climates. However, there are types of failure such as permanent deforestation (rutting) that are believed to be more acute and serious in hot climates rather than cold ones due to the fact that severe temperature increases in the asphalt pavement can result in a reduction of HMA stiffness resulting in deformation, which especially affected by heavy traffic loading [8-12]. Common deterioration occurring in HMA pavements is caused by heavy traffic loading as shown in Figure 2, cold or hot environment or climate, as well as the application of unsuitable materials and other causes, such as utility cuts exerted from outside. However, recent studies hypothesize a close relationship between surface cracking and non-uniform distribution of 3D contact pressure measured between the pavement structure and vehicle tires $[12,13]$. The results ensuing from the free-rolling car and truck tire measurement confirm that in addition to the usual contact pressure affecting the contact area, there is a considerable pressure produced by longitudinal and transverse contact [14]. 


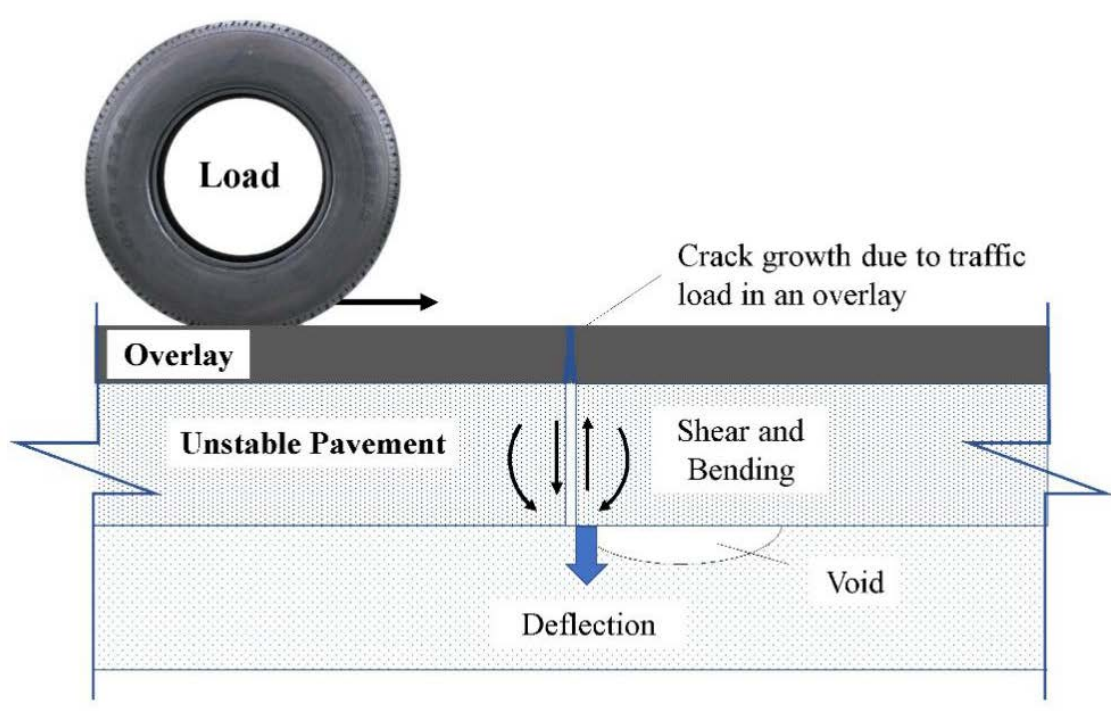

Figure 2. Loading and stresses in asphalt pavement.

Furthermore, longitudinal surface cracks are mostly expected in hot climates, usually as a result of huge transverse tensile stress concentrations near the edges of the tire. Another cause for surface cracking is the horizontal tensile stress exerted on the asphalt layer by repetitive cycles of fluctuations in more unstable temperatures expected in some regions with extreme and unstable climate conditions [15]. In general, the well-known deterioration of pavements includes cracking, rutting, raveling and bleeding and in the next part some of the most prevalent types of pavement deterioration are described.

\subsubsection{Cracking}

Cracking is the type of cracks in the bituminous pavement include alligator, edge, block, longitudinal and slippage cracking. The most prevalent one is alligator cracking. Alligator cracking, which is also known as fatigue cracking, is a series of interconnected cracks that usually occur on HMA pavement surfaces. Due to the apparent similarity between this kind of cracking and the ones on an alligator skin, it is called alligator cracking. Alligator cracks often results from continuous loads of heavy traffic on the tire pressure area on asphalt pavement. Fatigue cracking mostly occurs due to weakness in the sub-grade or base coarse, insufficient pavement thickness, excessive loading or a combination of all or some of the listed factors $[16,17]$.

\subsubsection{Rutting}

Rutting and pavement deformation is one of the most common problems that HMA pavements have suffered during recent decades. Rutting refers to the permanent deformation that occurs on pavements, in areas around the wheel path formed by heavy traffic loading [14]. Rutting usually results from the heavy loading exerted by the tires of heavy vehicles in the areas with high traffic volume. Rutting is the earliest distress occurring in a short time, usually a few months from the road launch, due to failure of the asphalt layers and the sub-grade soil under heavy pressure exerted by traffic loading. In order to resist this deformation, the employed HMA needs to have adequate density, which can be achieved through sufficient compaction during construction. Rutting can also ensue from an inappropriate mixture of ingredients, such as high bitumen content, high amount of round aggregate in the mixture and excessive filler or inadequate thickness of asphalt layer. Employment of excessive bitumen can lead to a reduction of friction among the particle of aggregate in the mixture, which, in consequence, contributes to greater conveyance of the load tolerance by the bitumen cement rather than the aggregate structure. In brief, rutting is a result of inadequate HMA thickness, poor compaction or weakness of pavement layers 
resulting from moisture infiltration or the application of low quality in making the asphalt mixture $[9,13]$.

\section{Fiber Application and Classification}

Fibers as a stabilizer have some advantage for bituminous mixture. A fiber modified mixture not only leads to a considerable reduction in the reflective and fatigue cracking as well as overall pavement maintenance and construction expenses $[16,18,19]$. It also increases the optimum bitumen content and void-percentage in the mixture [20]. The fibers bring about the modifications in the degree of mixture visco-elasticity through absorbing light bituminous components, which also helps to resolve the bitumen draindown problem [21,22]. Some other advantages that fiber modified mixtures produce in bituminous mixture are an improvement in its moisture susceptibility (though increasing the bitumen film thickness and rutting resistance [19-21].

The history of applying fibers in brittle matrix materials goes back, at least, 3.5 millenarian to the time when straw reinforced sun-baked bricks were commonly employed for the construction of buildings such as AqarQuf with $57 \mathrm{~m}$ height in the vicinity of ancient Baghdad in Mesopotamia. In the last 100 years, nevertheless, asbestos fiber was more common for the reinforcement of cement products and, for about 50 years, cellulose fiber, and, finally, within the last 30 years, glass fiber and polypropylene have been applied to the production of such construction mixtures [22]. In the case of bituminous pavement, Zube, who applied metal fiber reinforce bitumen in the early 1950s [19], was the first person to establish the modern way of boosting bitumen by fiber, which has now turned into a widespread and well-known reinforcing agent in the production of other mixtures, such as cement concrete and bituminous concrete.

Fibers can be processed in two ways; wet and dry. In the wet process the fibers are combined with the asphalt cement prior to adding the binder, while, in the dry process, the fiber is blended with the aggregate before bitumen is added to the mixture. Therefore, the dry process is generally more preferable to the wet process because of the following reasons: the dry process is the most feasible process to execute through which the fiber can be easily injected and distributed in the mixture; in the dry process fibers do not melt in the bitumen; and the dry process reduces the possibility of fibers clumping or balling in the mixture. However, it should be noted that fiber must be dried as much as possible before being added into the mixture to guarantee adequate adhesion to the bitumen binder and prevent any probability of stripping resulting from moisture [20-22].

Fibers can be classified into various categories through different ways. For instance, one way is dividing them into apparel and non-apparel ones, based on the final application of the fibrous material. The apparel fibers include some synthetic fibers such as nylon, polyester, spandex and some natural fibers such as cotton, jute, sisal, ramie and silk, whereas, non-apparel fibers include aramid, polyethylene, steel, copper, carbon, glass, silicon carbide and alumina. The non-apparel fibers are applicable to making cords and ropes, geotextiles and other structural applications, such as reinforcement of various composites. These fibers are highly stiff and strong and hardly fail in contrast to the apparel ones. Non-apparel fibers can also be characterized through complicated processing and drastic degradation with small flaws, which means they are usually less tough $[19,22]$. Another way of classification of fibers is according to their length, which is divided into continuous and staple fibers. The length of continuous fibers is, in fact, infinite while staple ones are short and discrete $(10-400 \mathrm{~mm})$. Staple fibers are also to be spun into yarn, such as continuous fibers, an ability which can be improved in case the fiber is imparted a crimp or waviness. Therefore, staple fiber is the best choice for bulkiness filling, filtration and similarly. Generally, staple natural fibers (such as cotton, wool) and staple synthetic fibers (such as nylon, polyester) are mixed to produce a fiber with the optimal characteristics made of both [20]. The application of fibers to structural engineering depends on their three important features, namely diameter, high flexibility and high aspect 
ratio (length/diameter, L/d) allowing a considerable fraction of the load to be conveyed through the matrix to the strong and stiff fiber in a composite reinforced with fiber $[19,22]$.

However, the most important characteristics of fibrous material are its properties' bias with its length. In general, fiber, especially continuous fiber, is highly preferred due to the above reasons. The aspect ratio (length/diameter) in a given material in a fibrous form is high making it considerably flexible, a feature that allows fiber to be converted into yarn, which, in turn, can be knitted, braided or woven into complex textures with various forms and shapes. There are some materials with inherent brittleness in their bulk such as glass, alumina, silicon carbide, etc. these kinds of fiber can be made as flexible as any other organic textile fiber, such as nylon, which is commonly used in making women's stockings. As mentioned earlier, fibrous material is highly strong and elastic as in highly orientated fiber. These features have been the main reason for the rapid development of fiber-reinforced composites with various matrix materials such as metals, polymers, ceramics and glass $[20,21]$. According to $[18,19]$, the fibers can be classified as straight, deformed, rippled, with special ends (e.g., enlarged or hooked ends) and with irregular cross sections. Straight and round steel fibers are generated through cutting thin wires with a 0.01 to 0.04 diameter $(0.25$ to $1 \mathrm{~mm})$ into pieces. Flat and straight steel fibers are produced in two ways, i.e., either by flattening wires or shearing thin sheets (approximately 0.15 to $0.41 \mathrm{~mm}$ ). The width of these fibers range between 0.25 and $1 \mathrm{~mm}$. Deformed and crimped fibers are produced through crimping the full length or enlarged or bent at both ends solely $[4,18]$.

Asphalt absorption of fibers leads to an increase in the viscosity of the asphalt, and, as a result, improvement of the interface adhesion strengths. In the meantime, however, the optimal asphalt contents produced through Marshall mixture design showed some increase, resulting, ultimately, in the improvement of the AC mixture flexibility due to the formation of more asphalt films, which enhance the performance of the aggregate as well as the heating and filling in the micro-cracks[20-23]. Furthermore, fiber bridges the asphalt holding them reallocates stress when cracking shows, providing more flexural strain and strength. The obtained results also confirmed that the AC mixes enriched with asbestos and lignin fibers will have stronger flexibility with lignin having even higher flexural strain than polymer reinforced mixtures. A significant reason for such a difference is the specific surface area, which is influential in the stabilization and absorption of asphalt resulting in the improvement of the $\mathrm{AC}$ flexibility and its resistance to cracking due to many interwoven branches in lignin and asbestos without any uniform size. Lignin fiber also has a porous structure with uneven surface area, which, in turn, increases its absorption capacity and ability to retain the bitumen binder and aggregate together [24].

\section{Fiber as Additive in Asphalt Mixtures}

Fiber is employed in the construction of roads, especially in gap-graded mixtures such as stone mastic asphalt, SMA and OGFC (open graded friction course) to improve their rutting resistance and fatigue life and drain-down of the asphalt pavement. The structure of SMA is based on "stone on stone" using a high proportion of large aggregates or stones adhering to each other making a strong structure for transferring the loads and high resistance to plastic deformation. Open graded friction asphalt (OGFC) has various benefits, such as improving the skid resistance, however, contains a higher percentage of large sized stones and a smaller proportion of smaller and finer stones and particles (less than $1.18 \mathrm{~mm}$ ). SMA, however, usually has a higher percentage of larger stone and fine particles (Asphalt Institute, Lexington, KY, USA, 2007). OGFC fibers can be organized into groups: (1) fibers with a high modulus of elasticity, such as asbestos, glass and carbon, which are less appropriate for asphalt random desperation; and (2) fibers with a low modulus of elasticity, which are more versatile and are able to be used in the construction of road pavements since during the pavement process then fibers undergo heavy traffic loading causing compaction in which sharp angular stones could cause damage to the fibers making high elasticity modulus fibers very vulnerable to breaking and damage [20-23]. 
Bituminous pavements are vulnerable to cracking and rutting under susceptible to temperature fluctuations, such as low temperature, which can result in cracking; medium temperature, which imposes fatigue on it; and high temperature, which ends up with a rutting problem. In the line with such facts, to change and modify the composition phase, thereby enhancing the engineering properties of the bituminous mixture through the injection of different additives, is among the common remedies. These additives are mainly composed of organic polymers and various other kinds of fibers reviewed in numerous literature resources. Fibers are usually utilized to boost the engineering properties of the bituminous mixtures through modification of the bitumen binder in the mix [23].

One of the main materials used in pavement mixture is bitumen, which is utilized in bituminous pavement construction since it is composed of strong cement and is highly waterproof, durable and adhesive. Bitumen is a plastic material that provides the mixtures of mineral aggregates with controllable flexibility and contains the asphaltenes, aromatic hydrocarbons, resins and saturates [19]. The light molecular weighted saturate component is readily absorbed by fiber due to its surface physical absorption function. Therefore, among different bitumen modifiers, fibers have gained significant attention because of their efficient improvement and impact on the rheological properties of bitumen binder and optimum bitumen content required for the mix design, which significantly contributes to the creation of interface bonding interconnecting the bitumen and fiber. Many studies confirm that fiber generally enhances the optimum bitumen content in the design of the mixture and halts the bitumen leakage due to its asphalt absorbing capability. Fiber modifies the viscos-elasticity, susceptibility against moisture, increases resistance to rutting and compliance with creep, as well as lowers the pavement reflective cracking. In addition, fiber enhances the features, such as anti-cracking in low temperature, durability and fatigue life of the bitumen mixes. It can also improve the material toughness, the tensile strength, the dynamic modulus and elasticity based on the fiber type and geometrical and physical properties [18].

The impact of fiber addition to bitumen concrete depends on the fiber properties (e.g., fiber length, diameter, surface texture, etc.) fibers that are too long may lead to a problem known as "balling". Balling is a problem that cases fibers to accumulate and form lumps; hence, preventing the fibers from easily and effectively mixing with the bitumen. Similarly, fibers that are too short may be able tom reinforce the mixture effectively and adequately. Another crucial parameter influencing fiber reinforcement effects is the length/diameter ratio of the fiber. Fibers with a bigger length/diameter ratio are able to interweave more easily to form a system of networking [24-27]. As many other researchers and studies confirm, then optimum fiber content within a mixture is $0.3 \%$ to $0.4 \%$ depending on the type of fiber used. Moreover, mixing more fibers than the optimum concentration is not economical since excessive reinforcement can result in brittle mastic, which, ultimately, may lead to the deterioration of the pavement in a short time. The best solution for this problem is an even uniform fiber distribution in a mixture [27].

\section{Review of Various Fibers in Bituminous Pavement}

\subsection{Asbestos Fiber}

Asbestos is advised as the exclusive textile mineral fiber that can be obtained from the reins of serpentine rocks. Generally, non-synthetic fibers, such as cotton and asbestos fibers, used to be employed in pavements [9]. In Arizona in the United States, an asbestos fortified mixture was also one of the five mixtures used for treatment and reinforcement of asphalt mixtures to prevent problems such as reflective cracking. In an observational study carried out on the role of fibers in reinforcing and stabilizing binders, water absorption, mesh-basket drain-down and oven heating are included. All the experiments focused on five kinds of fiber, i.e., a Polyacrylonitrile, two polyesters and lignin and asbestos, to assess and evaluate the absorption capability and stability of the fibers. During the tests, the microstructures of the fibers were carefully observed through employment of SEM. The outcomes confirm that the fibers can efficiently lead to improvement of resistance of the 
asphalt binders against flow and rutting, as well as dynamic shear modulus. The network impact of polyester and Polyacrylonitrile is apparently greater than that of the asbestos, and lignin is further strengthened by its antenna feature. The water absorption capability of lignin fiber is highest although its thermos stability is the lowest. However, the asbestos and lignin have a greater impact on absorption and stabilization of asphalt than polymer fibers since the specific surface areas of lignin and asbestos are larger in comparison [28].

In another similar research [24], studied the effects and mechanisms of fiber reinforcing asphalt concrete (AC) in various environmental conditions. He used four types of fiber in his study, i.e., polyester, asbestos, lignin and Polyacrylonitrile. Laboratory experiments were conducted on the AC (FRAC) reinforced by each of the fibers, to gauge its strain, strength and fatigue. The results also confirmed the significance of the improvement is also momentous in strength and strain and split indirect tensile strength (SITS). The studies confirmed greater flexural strength and resistance against strain in mixtures reinforced with asbestos and lignin, perhaps due to the higher stabilization they give to asphalt [24].

Studies on and about the mechanical and volumetric features of fiber-reinforced mixture using four different fibers, i.e., Polyacrylonitrile, polyester, asbestos and lignin, support that the optimum content, air voids, voids in minerals aggregate and Marshall stability of the asphalt mixture increase, but its bulk specific gravity shows a reduction. Marshall stability, optimum asphalt content and dynamic stability first increase but later decrease when more fiber is added into the content. The results of this study also confirm that Polyacrylonitrile and polyester fibers are highly stability as a result of the higher networking effect, but asbestos and lignin fibers lead to higher OBC and VFA because of their capability of asphalt absorption [20].

\subsection{Polyester Fiber}

Polyester is a polymerized substance obtained from crude oil from which asphalt is obtained as well [25]. Polyester fiber can be utilized to produce durable and strongly reinforced bitumen mastic required for hot climates. A research carried out by Putman on the effects of fiber on SMA revealed that adding polyester fibers to the mixture results in more significant improvements in the mixture toughness than the cellulose fiber can bring about. This confirmed that polyester fiber has a better capability to fill the cracks developed during the loading period; hence, resulting in increase of toughness of mixture. Furthermore, it indicated the creation of a stronger bond between the asphalt and polyester fibers than the cellulose fibers. The cellulose fiber had the highest stabilizing capacity to drain-down followed by polyester fiber. The mixture with the polyester fiber is expected to suffer less from rutting followed by tire, carpet and cellulose fiber [19].

Chen and Lin [25] focused on the fiber reinforcement mechanism of bitumen. The fibers he used in his experiments included rock wool, cellulose and polyester, which were injected into the bitumen mixture. The results showed that the fiber reinforcement increased the bitumen tensile strength while creating a strong adhesion between fibers and bitumen at the same time. Strong adhesion between bitumen and fiber improves the load-carrying capability of the mixture. The melting point of polyester is approximate $280{ }^{\circ} \mathrm{C}$, which helps the mixture to remain intact in hot conditions. Polyester can easily be entangled thereby increasing the softening point. These results have also been confirmed by the penetration test. Wu et al., [26] investigated the polyester fiber effects on the properties of fatigue and rheological features of asphalt, indicating that increasing polyester fiber content increases the asphalt binder viscosity, specifically in colder conditions since polyester fibers forms a localized network increasing the OPC in polyester fiber reinforced mixtures. Their study confirmed that adding fiber can improve the asphalt fatigue, especially when the stress levels are lower.

A study by [28] also conducted a research on the physical properties of fibers, their reinforcing effects and role in stabilization and reinforcement of asphalt binder with polyesters, Polyacrylonitrile, lignin and asbestos, indicating that fibers can effectively result in a significant improvement in resistance of the asphalt binder against flow, rutting and dy- 
namic shear modulus. Apparently, Polyacrylonitrile and polyester fibers have a significant network effect in comparison to the asbestos and lignin fibers, in which the antenna features intensify the produced effect. Polymer fibers have lower asphalt absorption and stabilization than asbestos and lignin fiber. A study by [23] also studied the fatigue properties and dynamic response of fiber-reinforced asphalt mixes. Their study indicated that fiber could improve the fatigue property. The results obtained from the fatigue test confirmed that the fiber-reinforced mixtures are more resistant to fatigue than the control mixture. This can be a result of the fiber role in distracting the stress exerted on asphalt mix preventing the appearance of cracks in later stages. Polyester fiber considered as the most optimum fiber, which can contribute to the improvement of the resistance of asphalt mixtures against fatigue.

\subsection{GLASS Fiber}

This kind of fiber is mainly employed for glass fiber-reinforced cement (GFRC) sheets as well as in bituminous pavement. The history of glass fiber is not very clear. However, glass fiber is highly resistant to thermal and chemical changes, has high tensile strength and excellent insulating features. Glass fiber is also resistant against fire, is used in electrical insulation and has a dimensional stability against thermal modification enabling it to have a high softening point, $815^{\circ} \mathrm{C}$ [18]. There are some industrial applications including asphalt-roofing and flooring products, fillers, battery separators, radiant heat and fire barriers. Glass fiber is very resistant to damage and cracks, which are expected in roofing shingles. A common application of this kind of fiber is in road pavement construction and overlay to reduce the reflective cracking effects $[9,18]$.

It is believed that the injection of glass fiber into asphalt mixes increases its strength and fatigue life and ductility. As a result of its high mechanical characteristics, glass fiber is an optimal choice to modify paving asphalt mixtures. With new technologies applied to the reduction of glass fiber, glass fiber reinforced mixtures are more cost effective in comparison to mixtures modified with other fibers. Application of glass fiber-reinforced mixes can result in high construction cost although the maintenance cost might be reduced [27]. The factor of critical stress intensity or fracture toughness for FRAC is higher in comparison to those for the plain asphalt mixtures, including a higher resistance to propagation of cracks. Glass fiber reinforced asphalt mixture is expected to result in improvement of the stability and deform ability without any need for increasing the bitumen content of HMA, which is influential in preventing problems, such as bleeding and rutting and bleeding at high temperatures in hot regions or seasons. Glass fiber is used for pavement construction and paving in new applications such as Glasgrid (advanced fiber glass technology) to increase the resistance of pavement overlay to reflective cracking [27]. Current study by Tanzadeh et al., 2019 [29] showed that glass fiber modified asphalt of Open-graded friction course (OGFC)reduced the permeability, reduce the sensitivity to oxidation and enhancing the tensile strength. In addition, The moisture sensitivity of the OGFC mixtures with glass fiber was better than that of the basalt fiber (Tanzadeh et al., 2019) [29].It seems that glass fiber has significant impact in improving the mechanical properties of the asphalt mixture, in term of better resistance to permanent deformation and long term live service durability.

\subsection{Cellulose Fiber}

Cellulose fibers are among the important fibers employed both in concrete and in bituminous mixtures worldwide. Some of the advantages of wood fiber are its high tensile strength, immediate availability and high elasticity modulus. Cellulose fiber allows asphalt to increase resulting in a decrease of binder bleeding. No significant modifications were detected in abrasion or void content after the injection of cellulose fiber. Previous research conducted on the effects of loose cellulose fiber, pelletized cellulose fiber and two other polymers. The reinforced mixes were tested and evaluated for damage, such as drain-down, rutting, cracking and aging. Drain-down experiments showed that all binder mixes reinforced with fiber significantly drained less than the control mixtures or 
mixtures reinforced with polymers. Fiber reinforced mixes are the only mixes to meet the specifications of the test for drain-down. The control specimen had high resistance against rutting. There was no significant difference between the modified and control mixtures. However, polymer reinforced mixes showed higher resistance to the aging problem [28-30]. Studies showed that applied different asphalt contents reinforced with cellulose fiber to the study of SMA. The prepared mixes were evaluated using a thermal stress restrained sample and indirect tensile tests. Clumping was one of the main problems that occurred during the mixing process. Increasing the temperature of the mixture and the mixing duration resulted in improvement of the fiber distribution; however, some clumps still remain in the mixture. The authors concluded that poor fiber distribution could cause the unsatisfactory improvement, suggesting the need for future experiments to substantiate their theory [27].

Cellulose fiber was used in another research on SMA. The experiments included binder drain-down, moisture susceptibility (tensile strength ratio) and static creep modulus as well as a recovery efficiency. Fiber was injected into mixes containing polymer modified and standard binders. The results concerning the binder drain-down showed significant improvements in all the mixes reinforced with cellulose fiber. Both plain mixtures and fiber modified ones showed high indirect tensile strength. The tensile strength ratio resulted in induction of damage in all the tested mixtures. The mixture modified with fiber demonstrated lower tensile strength and resistance to humidity than a polymer modified one; however, statistical and variable analyses support efficiency and creep modulus are better fiber reinforced mixes and plain binders than those reinforced with fiber and polymer $[17,27]$.

The application of cellulose fibers in OGFC mixtures were studied and evaluated. The evaluation covered field and laboratory phases in Georgia. Their samples indicated six combinations of additives and polymer binder. The laboratory test included OGFC mixtures reinforced with both mineral and cellulose fibers, performing many other moisture sensitivity experiments. It was hypothesized that rain could result in the absorption of water by the cellulose fiber and, ultimately, its premature failure. Thus, mineral fiber was more preferred in humid regions since it does not absorb moisture. Further findings of this study revealed that the performance of cellulose fiber is comparable to mineral fiber on the results achieved in both the lab and field, indicating that the performance of cellulose fiber was similar to that of mineral fibers in OGFC mixtures. These mixtures were monitored on Belgian roads for their resistance to drainage over about six months. Fiber reinforced mixtures retained their drainage quality over the period, while in mixtures without fiber the drainage was approximately doubled [18].

The effects of fiber (including cellulose fiber) and polymer modifiers in SMA were investigated $[18,29,30]$. They reported that fiber modified mixtures demonstrated little improvement in the strength features of the prepared samples but showed significant reduction in permeability. However, the injection of polymer into the mixture approximately doubled its strength and permeability, also increasing the number of air voids. When polymer and fiber are applied together, the mixture showed further strength improvement without a significant improvement in permeability. Hassan [31] studied the impact of cellulose fiber and styrene butadiene rubber (SBR) polymer mixed and processed in an open-graded friction course (OGFC). The results indicated that the role of polymer is more significant on the mixture's resistance to problems, such as raveling in the short-term in comparison with the significance of the cellulose fiber in this role. Both the used fiber and polymer showed roughly the same effect in the long-term resistance of OGFC to raveling as gauged through the aged abrasion test. As the results confirmed, the fibers also play a more significant role in reducing the drain-down problem than polymer. In another experiment, Tayfur applied five modified asphalt mixtures including polyalphaolefin, polyolefin, bituminous cellulose fiber and styrene butadiene styrene to define the performance of rutting in asphalt mixtures. Some tests, such as indirect tensile strength, repeated and static creep and LCPC tracking was carried out. The mixtures reinforced with various additives displayed different performance levels. However, all mixture samples displayed 
higher resistance to the problem of permanent deformation. Cellulose fiber possessed the most optimal bitumen content, as obtained from the Marshall test. This result is expected due to the wide specific surface area and high bitumen demand of the cellulose fiber. The improvements in indirect tensile strengths of the reinforced mix led to better resistance of the mixture to the problem of permanent deformation as confirmed by the LCPC wheel tracking test at $60^{\circ} \mathrm{C}$. Relevant researchers believe that modification of the mixture can also contribute considerably to the generation of adhesion among components and aggregates of HMA [32].

By applying microscopic and rheological tests, Chen [25] studied bitumen mixtures reinforced with cellulose, rock, wool and polyester. They concluded that the application of these fibers contributes to the enhancement of engineering properties of the mixture, such as viscosity, toughness and tenacity. The results of the achieved tests indicate that reinforcement of the mixture with fiber significantly increases the engineering properties of the mixtures. Hotter mixing conditions increase the viscosity ratio between the mastic and the bitumen.

The results showed that the bitumen-fiber mastics tensile strength also increases with more injection of fiber since it reduces a fraction of the tensile loads. High tensile strength is a sign of strong adhesion among the fibers and bitumen. Scanning electron micrographs illustrate that bitumen is reinforced by fiber in a 3D structure. Nevertheless, when fibers commence interacting with one another there is a critical fiber fraction that reduces the toughness of the mixture. The OFC depends on the type of fiber, its diameter and length. Adding more fiber into the bitumen mixture increases its stiffness, thereby reducing the possibility of drain-down problem. The stabilizing impact of fiber reinforced bitumen can be explained based on the 3D network in the microspores. High adhesion among fibers and bitumen increases the bitumen-fiber mastic load-carrying ability [33].

Chen [25] concluded that adding cellulose or mineral fiber results in similar behavior in bitumen reinforcement. Polypropylene fibers, however, have a strong tendency to entanglement, leading to higher points of asphalt mixture softening. In cases where reinforcement of bitumen-fiber mastics is required in hot conditions, polyester fibers can be employed. The standards applied to the selection of an optimum fiber concentration are, among others, viscosity, softening point, toughness and tenacity and viscosity properties. The engineering characteristics and economic factors gain more significance when the right fiber content is determined for asphalt mixes. A study by [26] conducted a research on the effects of cellulose and polyester fibers on the porous asphalt mixes engineering properties through drain-down, abrasion, volumetric properties, rutting and moisture damage testing. The images of scanning electron microscopy were used to identify the microstructure of the fiber. The influence of rutting parameter' $\left(\mathrm{G}^{*} / \sin \delta\right)$ of fiber-reinforced asphalt by different fibers in the resistance of the mixes to rutting was studied. The experimental results that fiber stabilizes the asphalt binder by thickening the asphalt film covering the aggregates. The SEM images indicated that the surface texture of polyester fiber is relatively smooth in comparison to that of $C$ fiber. However, it should be noted that they can be soaked easily by surface active components in the asphalt. In other words, P fiber can absorb the asphalt and prevent or reduce drain-down. In addition, they result in a slight improvement of the mechanical strength of porous asphalt mixtures at high temperatures. As comparison analysis confirms, cellulose fibers appeared to have better performance than polyester fibers in porous asphalt mixtures.

The dynamic properties of fiber-reinforced mixture of asphalt were studied [26]. In this study, polyester, cellulose and mineral fibers were applied as additives to the mixture specimens. The results of the experiments show that all fiber-reinforced mixtures possess higher dynamic modulus than the control mixture. Cellulose fiber was also injected into recycled asphalt concrete (RAC), as a supplementary substance. The outcomes of the experiment showed that the addition of fiber results in a significant improvement of the fundamental RAC performance in terms of rutting resistance, moisture susceptibility, resistance to cracking and durability. Wu [23] concluded that RAC mixed with reinforced 
binder up to $70 \%$ is the best suggestion for the optimal and balanced asphalt mixture. Another study [23] also investigated the dynamic response and fatigue properties of fiberreinforced mixtures modified with three kinds of fiber, i.e., cellulose, polyester and mineral. The tests of dynamic modulus employing the Superpave simple performance tester (SPT) and test of indirect tension fatigue (ITFT) were utilized. It was concluded that the specimen mixtures modified with different fibers showed lower dynamic modulus, indicating that the fiber-modified mixture stiffness can be reduced, resulting in an improvement of the mixture flexibility and modification of visco-elastic properties of the specimen mixtures. The fatigue parameter derived from the measurement of the dynamic response was used to elevate the mixture resistance to fatigue. As a results support, the fiber-reinforced mixtures fatigue parameters decreased, thereby indicating that this could result in the improvement of the fatigue properties of the fiber-modified mixtures. The results of the test on fatigue further illustrated that fiber-reinforced mixtures have better resistance to fatigue than the control mixture.

\subsection{Waste Fiber}

Recycling waste materials produced in urban areas has turned into a critical issue in recent decades. There has been numerous research to identify ways to reduce the landfills and environmental pollution resulting from the disposal of waste materials. In addition, waste material can be used as waste fiber derived from manufacturing processes that are commonly delivered to landfills. This measure not only reduces environmental pollution and the expense of waste material transportation to landfills but also contributes to the improvement of the engineering properties of bituminous asphalt mixture [23,33]. In a study [19] applied the waste fibers produced by industrial plants and workshops such as scrap tires and carpet fiber to the enrichment of SMA. Their study revealed that there is no significant difference between the engineering properties and the performance of SMA reinforced with scrap tires and carpet fiber and the SMA with cellulose or other types of polyester fibers commonly used in hot mix asphalt (HMA). The study also revealed that there is no significant difference between these two mixtures in moisture susceptibility and permanent deformation. However, adding waste tires, carpet fiber and polyester fiber considerably improves the mixture toughness more than cellulose fiber. Waste tires and carpet fiber also have a preventive role in controlling excessive SMA drain-down. The mixture specimen with waste tires did not result in a loss or reduction of toughness when conditioned in moisture. It can be concluded from the findings of this study that scrap tires and carpet fiber are optimal options to be employed as stabilizers of SMA. In addition, these fibers maintain the performance of moisture susceptibility and permanent deformation. Employment of the waste is more cost effective and will definitely lead to prediction of the environment [19].

In summary, the application of fiber in asphalt modification is significant and showing an obvious impact of producing a modifier binder with environmentally friendly method. The encouraging of utilizing types of fiber-reinforced in asphalt pavement mixture contains waste fiber, cellulose, glass fibers and synthetic polymer [34,35]. However, the suitable fiber content to be used in a specified mixture may become practically standard for certain fiber types. For instance, $0.3 \%$ by weight of the mixture is an ordinary addition rate for the waste and cellulose fibers in stone-matrix asphalt (SMA). Alternatively, using a high percentage of fiber could result in difficult compaction, and, as such, leading to higher air void contents. In good compaction, there must be a good adhesion between the fiber and the asphalt binder [36]. Several researchers have proven that fiber-reinforced-asphalt mixture mainly achieved better performance properties than that of the control mixtures, in term of thermal cracking and resisting permanent deformation, and would occasionally perform better in fatigue [37-39]. The fiber-reinforced- asphalt mixture revealed the highest stress, and the mixer proved flow numbers 15 times better than the control mixture in the repeated load permanent deformation test $[40,41]$. Furthermore, the results in indirect tensile testing at low temperatures $\left(0{ }^{\circ} \mathrm{C},-10{ }^{\circ} \mathrm{C}\right.$ and $\left.-20^{\circ} \mathrm{C}\right)$ indicated that the fiber 
mix would be more resistant to thermal cracking, with strength 1.5 times greater than the control. In addition, the fiber mix demonstrated higher fracture energy, which relates to reduced thermal cracking $[40,41]$.

\section{Conclusions}

The outcomes confirm that the fibers can efficiently lead to improvement of resistance of the asphalt binders against flow and rutting, as well as dynamic shear modulus. The network impact of polyester and Polyacrylonitrile is apparently greater than that of the asbestos, and lignin is further strengthened by its antenna feature. Apparently, Polyacrylonitrile and polyester fibers have a significant network effect in comparison to the asbestos and lignin fibers, in which the antenna features intensify the produced effect. On other hand, glass fiber is highly resistant to thermal and chemical changes, has high tensile strength and excellent insulating features. Glass fiber is very resistant to damage and cracks, which are expected in roofing shingles. The results showed that despite the improvement of the resistance of the polymer modified mixture to cracking, the mixture reinforced with cellulose did not show any significant improvement in the low temperature performance, indicating the significance of the role of polymer in the positive modification of the mixture samples. The effects of fiber content and type of SMA rutting performance, cellulose fiber and mineral were applied to the specimen and the achieved result showed that the fiber content and type can lead to modification of the SMA rutting performance. The optimum bitumen content and indirect tensile strength of the cellulose fiber reinforced mixture is higher.

Author Contributions: Conceptualization, N.M.; methodology, N.M.; validation, N.M., M.K. and A.M.; investigation, N.M.; resources, N.M. and F.K.; writing-original draft preparation, N.M.; writing-review and editing, N.M., N.S. and A.M. All authors have read and agreed to the published version of the manuscript.

Funding: This paper received no external funding.

Data Availability Statement: not available.

Conflicts of Interest: The authors declare no conflict of interest.

\section{References}

1. Yildrim, Y. Polymer modified asphalt binder. J. Build. Constr. Mater. 2007, 21, 66-72. [CrossRef]

2. Ali, A. Influence of Crumb Rubber Modifier on Performance Characteristics of Stone Mastic Asphalt. MSc. Dissertation, University of Malaya, Kuala Lumpur, Malaysia, 2013.

3. O'Flaherty, C.A. Highway Engineering Textbook, 3rd ed.; Edward Arnold: London, UK, 1988.

4. Mashaan, N.S.; Hassan, A.; Karim, M.R.; Aziz, M.A. A Review on Using Crumb Rubber in Reinforcement of Asphalt Pavement. Sci. World J. 2014, 2014, 21. [CrossRef]

5. Mahrez, A. Properties and Performance of Stone Mastic Asphalt Reinforced with Glass Fibre. Ph.D. Thesis, Faculty of Engineering, University of Malaya, Kuala Lumpur, Malaysia, 2008.

6. Al-Hadidy, A.; Yi-Qiu, T. Effect of polyethylene on life of flexible pavements. Constr. Build. Mater. 2009, 23, 1456-1464. [CrossRef]

7. Al-Hadidy, A.; Yi-Qiu, T. Mechanistic approach for polypropylene-modified flexible pavements. Mater. Des. 2009, 30, 1133-1140. [CrossRef]

8. Abdullah, S. A Laboratory Investigation of Modified Binders in Bituminous Mixes. MSc. Dissertation, University of Malaya, Kuala Lumpur, Malaysia, 1996.

9. Piromanski, B.; Chegenizadeh, A.; Mashaan, N.; Nikraz, H. Study on HDPE effect on rutting resistance of binder. Buildings 2020, 10, 156. [CrossRef]

10. Mahrez, A. Properties of Rubberised Bitumen Binder and Its Effect on the Bituminous Mix. MSc. Dissertation, Faculty of Engineering, University of Malaya, Kuala Lumpur, Malaysia, 1999.

11. Arabani, M.; Mirabdolazimi, S.M. Experimental investigation of the fatigue behaviour of asphalt concrete mixtures containing waste iron powder. Mater. Sci. Eng. A 2011, 528, 3866-3870. [CrossRef]

12. Sousa, J.B.; Weissman, S.L. Modeling permanent deformation of asphalt-aggregate mixes. J. Assoc. Asph. Paving Technol. 1994, 63, 224-257.

13. Brown, E.R.; Cross, S.A. A National Study of Rutting in Asphalt Pavement. J. Assoc. Asph. Paving Technol. 1992, 61, 535-583. 
14. Tayfur, S.; Ozen, H.; Aksoy, A. Investigation of rutting performance of asphalt mixtures containing polymer modifiers. Constr. Build. Mater. 2007, 21, 328-337. [CrossRef]

15. Brown, E.R.; Hemant, M. Evaluation of Laboratory Properties of SMA Mixture; NCATR Report No. 93-5; National Center for Asphalt Technology, Auburn University: Auburn, AL, USA, 1993.

16. Ratnasamy, M.; Bujang, B.K. Laboratory diameteral fatigue performance of SMA with cellulose oil palm fiber. Am. J. Appl. Sci. 2006, 3, 2005-2010.

17. Hamed, F.K.M. Evaluation of Fatigue Resistance for Modified Asphalt Concrete Mixture Based on Dissipate Energy Concept. Ph.D. Thesis, Technische University, Darmstadt, Germany, 2010.

18. Abtahi, S.M.; Sheikhzadeh, M.; Hejazi, S.M. Fiber- reinforced asphalt-concrete-A review. Constr. Build. Mater. 2010, 24, 871-877. [CrossRef]

19. Putman, B.J.; Amirkhanian, S.N. Utilization of waste fibers in stone matrix asphalt mixtures. Reosurces Conserv. Recycl. 2004, 42, 265-274. [CrossRef]

20. Miao, Y.; Wang, T.; Wang, L. Influences of Interface Properties on the Performance of Fiber-Reinforced Asphalt Binder. Polymers 2019, 11, 542. [CrossRef] [PubMed]

21. Mashaan, N.S.; Chegenizadeh, A.; Nikraz, H.; Rezagholilou, A. Investigating the engineering properties of asphalt binder modified with waste plastic polymer. Ain Shams Eng. J. 2021, 12, 1569-1574. [CrossRef]

22. Mahrez, A.; Karim, M.R. Fatigue characteristics of stone mastic asphalt mix reinforced with fiber glass. Int. J. Phys. Sci. 2010, 5, 1840-1847.

23. Wu, Y.S.; Li, N. Investigation of the dynamic and fatigue properties of fiber-modified asphalt mixtures. Int. J. Fatigue 2009, 31, 1598-1602.

24. Xu, Q.; Chen, H.; Jorge, A.P. Performance of fiber reinforced asphalt concrete under environmental temperature and water effects. Constr. Build. Mater. 2010, 24, 2003-2010. [CrossRef]

25. Chen, J.; Lin, K. Mechanism and Behavior of Bitumen Strength Reinforcement Using Fibers. J. Mater. Sci. 2005, 40, 87-95. [CrossRef]

26. Wu, S.; Chen, Z.; Ye, Q.; Liao, W. Effects of Fiber Additive on the High Temperature Property of Asphalt Binder. J. Wuhan Univ. Technol. Mater. Sci. Ed. 2006, 21, 28-31.

27. Mahrez, A. Fatigue and Deformation Properties of Glass Fiber Reinforced Bituminous Mixes. J. East Asia Soc. Transp. Stud. 2005, 6, 997-1007.

28. Xu, Q.; Chen, H. Experimental study of fibers in stabilizing and reinforcing asphalt binder. Fuel 2010, 89, 71616-71622.

29. Tanzadeh, R.; Tanzadeh, J.; Honarmand, M.; Tahami, S.A. Experimental study on the effect of basalt and glass fibers on behavior of open-graded friction course asphalt modified with nano-silica. Constr. Build. Mater. 2019, 212, 467-475. [CrossRef]

30. Punith, V.S.; Suresha, S.N.; Raju, S.; Bose, S.; Veeraragavan, A. Laboratory Investigation of Open-Graded Friction-Course Mixtures Containing Polymers and Cellulose Fibers. J. Transp. Eng. 2012, 138, 67-74. [CrossRef]

31. Hassan, H.F.; Al-Jabri, K.S. Effect of organic fibers on open-graded friction course mixture properties. Int. J. Pavement Eng. 2005, 6, 67-75. [CrossRef]

32. Petit-Conil, M.; Lecourt, M.; Meyer, V. High-Yield Pulps: An Interesting Concept for Producing Lignocellulosic Fibers. In Lignocellulosic Fibers and Wood Handbook: Renewable Materials for Today's Environment; Wiley: Hoboken, NJ, USA, 2016. [CrossRef]

33. Wu, S.P.; Gang, L.I.; Mo, L.T.; Zheng, C.H.; Ye, Q.S. Effect of fiber types on relevant properties of porous asphalt. Trans. Nonferrous Met. Soc. China 2006, 16, 791-795. [CrossRef]

34. Phan, T.M.; Nguyen, S.N.; Seo, C.B.; Park, D.W. Effect of treated fibers on performance of asphalt mixture. Constr. Build. Mater. 2021, 274, 122051. [CrossRef]

35. Milad, A.A.; Ali, A.S.B.; Yusoff, N.I.M. A review of the utilisation of recycled waste material as an alternative modifier in asphalt mixtures. Civ. Eng. J. 2020, 6, 42-60. [CrossRef]

36. Gupta, A.; Castro-Fresno, D.; Lastra-Gonzalez, P.; Rodriguez-Hernandez, J. Selection of fibers to improve porous asphalt mixtures using multi-criteria analysis. Constr. Build. Mater. 2021, 266, 121198. [CrossRef]

37. Liu, K.; Li, T.; Wu, C.; Jiang, K.; Shi, X. Bamboo fiber has engineering properties and performance suitable as reinforcement for asphalt mixture. Constr. Build. Mater. 2021, 290, 123240. [CrossRef]

38. Guo, Q.; Chen, Z.; Liu, P.; Li, Y.; Hu, J.; Gao, Y.; Li, X. Influence of basalt fiber on mode I and II fracture properties of asphalt mixture at medium and low temperatures. Theor. Appl. Fract. Mech. 2021, 112, 102884. [CrossRef]

39. Li, N.; Zhan, H.; Yu, X.; Tang, W.; Xue, Q. Investigation of the aging behavior of cellulose fiber in reclaimed asphalt pavement. Constr. Build. Mater. 2021, 271, 121559. [CrossRef]

40. AL-Ridha, A.S.; Alkaissi, Z.A.; Kareem, S.M. Evaluating the influence of adding steel fibers on the moisture damage and aging resistance of hot asphalt mixtures. Mater. Today Proc., in press.

41. Zarei, M.; Abdi Kordani, A.; Zahedi, M. Pure mode I and pure mode II fracture resistance of modified hot mix asphalt at low and intermediate temperatures. Fatigue Fract. Eng. Mater. Struct. 2021, 44, 2222-2243. [CrossRef] 